\title{
Pola Unmet Need Kontrasepsi Modern di Indonesia: Analisis Lanjutan Data SDKI 2007, 2012 dan 2017
}

\section{Pattern of Unmet Need Modern Contraception in Indonesia: IDHS Data Analysis 2007, 2012 and 2017}

\author{
Yunita Amraeni $^{1}$, Sudijanto Kamso ${ }^{2}$, Sabarinah ${ }^{2}$, Purwantyastuti ${ }^{3}$ \\ ${ }^{1}$ Program Studi Kesehatan Masyarakat, Universitas Mandala Waluya, Kendari \\ ${ }^{2}$ Program Studi Biostatistik dan Kependudukan, Universitas Indonesia, Depok \\ ${ }^{3}$ Program Studi Farmakologi dan Terapi, Universitas Indonesia, Depok
}

\begin{abstract}
Abstrak
Unmet need KB berdasarkan data SDKI di Indonesia masih stagnan. Sementara konsep unmet need sesuai dengan program pemerintah yaitu unmet need alat kontrasepsi modern masih memerlukan identifikasi. Oleh karena itu, penelitian ini bertujuan untuk mengidentifikasi pola unmet need alat kontrasepsi modern di Indonesia berdasarkan karakteristik dan wilayahnya. Penelitian ini merupakan data sekunder dengan panel survei dengan pendekatan kuantitatif pada analisis Data Survei Demografi dan Kesehatan Indonesia SDKI 2007, 2012 dan 2017 dengan sampel utama adalah wanita usia subur (1549 tahun) baik yang menggunakan/tidak menggunakan suatu metode kontrasepsi. Penelitian dimulai dari penyaringan data, imputasi data dan analisis deskriptif. Kecenderungan kejadian unmet need meningkat sebesar $8 \%$ dalam sepuluh tahun terakhir dengan unmet need dengan tujuan menjarangkan meningkat $1,5 \%$ dan unmet need dengan tujuan membatasi meningkat 6,5\%. Tidak ada perbedaan karakteristik yang signifikan antara Pasangan Usia Subur baik di perkotaan maupun di pedesaan. Tren unmet need kontrasepsi modern meningkat seiring dengan meningkatnya penggunaan tradisional. dan peningkatan unmet need modern lebih dominan di Indonesia bagian timur, sehingga perlu adanya peningkatan promosi terkait penggunaan alat kontrasepsi modern di Indonesia dan perlu adanya perlakuan yang berbeda untuk peningkatan alat kontrasepsi modern sesuai dengan kondisi geografis dan sosial budaya setempat.
\end{abstract}

Kata Kunci: Unmet need, Kontrasepsi modern, Indonesia, SDKI

\begin{abstract}
The unmet need for family planning based on IDHS data in Indonesia is still stagnant. Meanwhile, the concept of unmet need is in accordance with the government program, namely unmet need for modern contraception, which is still requires identification. Therefore, the aim of this study is to identify patterns of unmet need for modern contraception in Indonesia based on characteristics and regions. This was secondary data with a survey panel with a quantitative approach which further analyzes the Indonesian Demographic and Health Survey Data for the 2007, 2012 and 2017 IDHS with the main sample being women of reproductive age (15-49 years) both using / not using a contraceptive method. The research started from data screening, data imputation and descriptive analysis. The tendency of the incidence of unmet need increased by $8 \%$ in the last ten years with unmet need with the aim to space increased by $1.5 \%$ and unmet need in order to limit the increase of $6.5 \%$. There is no significant difference in the characteristics between spouses of fertile age in both urban and rural. The trend of unmet need for modern contraception is increasing along with the increase in traditional use. and the increase in modern unmet need is more dominant in eastern Indonesia, so there is a need for increased promotion regarding the use of modern contraceptives in Indonesia and the need for different treatment for increasing modern contraceptives according to local geographic and socio-cultural conditions.
\end{abstract}

Keywords: Unmet need, Modern contraception, Indonesia, IDHS

Korespondensi : Yunita Amraeni

Email: zahra.kahfi@gmail.com 


\section{PENDAHULUAN}

Unmet Need adalah semua pria atau wanita usia subur yang sudah menikah namun belum terpenuhi kebutuhan kontrasepsinya, atau tidak menggunakan kontrasepsi, baik yang tidak ingin punya anak lagi ataupun menunda kelahiran berikutnya. Unmet need masih menjadi salah satu permasalahan utama dalam pencapaian program keluarga berencana di Indonesia. Data SDKI menunjukkan unmet need secara umum masih mengalami peningkatan setiap tahun. Selama beberapa dekade, terjadi unmet need setiap tahun dan mengalami stagnasi dengan angka masih relatif tinggi yang masih mencapai 11\% tahun 2017. Kesenjangan unmet need antar provinsi dan antarkab/kota masih tinggi dan terjadi kecenderungan peningkatan unmet need di beberapa provinsi. Persentase unmet need yang tertinggi berada di wilayah Papua Barat dengan angka 23,7\% dan terendah dengan angka 5,6\% di wilayah Bangka Belitung (1). Selain antar propinsi, terjadi pula disparitas antar wilayah urban dan rural. Disparitas unmet need di wilayah urban dan rural terjadi dari tahun ke tahun yang terlihat lebih tinggi pada daerah rural dibandingkan daerah urban.

Konsep data SDKI menunjukkan met need untuk penggunaan KB modern sementara untuk unmet need dengan konsep secara umum yaitu tidak menggunakan kontrasepsi dengan semua metode. Perubahan dalam konsep dan pengukuran unmet need dicetuskan oleh Westoff, dkk dengan memasukkan kontrasepsi tradisional ke dalam kategori unmet need (2) Hal ini juga didukung oleh beberapa rekomendasi studi yang mempertimbangkan kurang efektifnya metode tradisional $(3,4,5)$. Metode kontrasepsi tradisional menurut beberapa masyarakat cukup efektif mencegah kehamilan asalkan dilakukan secara disiplin. Namun, dari sisi pemerintah sebagai penyelenggara program pengendalian penduduk, metode ini masih memiliki peluang tinggi mengalami kegagalan hingga berakhir dengan kehamilan (6). Sehingga, sesuai dengan target program KB, maka diharapkan klien menggunakan kontrasepsi modern. Walaupun penggunaan kontrasepsi modern mengalami peningkatan secara nasional namun kecenderungan disparitas masih terjadi pada CPR cara modern (7). Oleh karena itu studi ini akan mengidentifikasi unmet need dengan konsep tidak menggunakan metode modern atau dengan kata lain tidak menggunakan kontrasepsi dan atau menggunakan metode tradisional.

\section{METODE}

Penelitian ini menggunakan data sekunder dengan panel survey pendekatan kuantitatif yang menganalisis lebih lanjut Data Survei Demografi dan Kesehatan Indonesia SDKI 2007, 2012 dan 2017 yang dilaksanakan di seluruh provinsi di Indonesia. Populasi target penelitian ini adalah semua Pasangan Usia Subur ( 15-49 tahun) di Indonesia yang menjadi sampel dalam SDKI 2007, 2012 dan SDKI 2017. Dalam penelitian ini, yang menjadi sampel utama adalah Perempuan Usia Subur (15-49 tahun) baik yang menggunakan atau tidak menggunakan suatu cara kontrasepsi. Tahapan penelitian mulai dari skrining data, imputasi data dan analisis deskriptif.

\section{HASIL PENELITIAN}

Karakteristik sampel penelitian

Karakteristik Individu diidentifikasi dengan sosiodemografi dalam penelitian ini adalah beberapa faktor yang berkaitan dengan keadaan diri pasangan usia subur serta lingkungannya 
didalam pengaruhnya terhadap unmet need kontrasepsi modern. Gambaran umur dikategorikan dengan umur rentan ( $<20 \&>35$ tahun) dan umur ideal (20-35 tahun). Kategori ini merujuk pada konsep Carlo Berleini et al., yang menyatakan bahwa umur ideal perempuan untuk kesiapan hamil dan melahirkan berada diantara 20 tahun - 35 tahun, sementara kurang atau lebih dari umur tersebut memiliki risiko tinggi terhadap kehamilan dan kelahiran(8). Tabel 1 menunjukkan bahwa umur ibu kategori rentan mengalami peningkatan dalam kurun waktu sepuluh tahun sebesar 10,7\%. Rata-rata umur ibu juga mengalami kenaikan dari tahun 2007 sebesar 33,94 menjadi 35,70 pada tahun 2017. Selama kurun waktu sepuluh tahun, PUS dengan jumlah anak sedikit $(\leq 2)$ semakin meningkat sekitar 5,9\%. Sebaliknya PUS dengan jumlah anak lebih banyak (>4) semakin berkurang 5,2\%. Begitupula halnya dengan pendidikan PUS mengalami peningkatan untuk pendidikan yang lebih tinggi sekitar 5,7\% dan 3,8 \% masing-masing. Dalam periode sepuluh tahun, persentase PUS dengan status bekerja tetap lebih besar dibandingkan dengan yang tidak bekerja. Sementara untuk kuintil kekayaan, tetap stagnan, tersebar rata sebesar $20 \%$ untuk masing-masing golongan.

Tabel 1. Gambaran Faktor Individu Pasangan Usia Subur Berdasarkan Wilayah Tempat Tinggal

\begin{tabular}{|c|c|c|c|c|c|c|}
\hline \multirow[t]{2}{*}{ Variabel } & \multicolumn{2}{|c|}{ SDKI 2007} & \multicolumn{2}{|c|}{ SDKI 2012} & \multicolumn{2}{|c|}{ SDKI 2017} \\
\hline & Urban & Rural & Urban & Rural & Urban & Rural \\
\hline \multicolumn{7}{|l|}{ Umur Ibu } \\
\hline Ideal (20-35 tahun) & 41 & 59 & 44,9 & 55,1 & 50,2 & 49,8 \\
\hline Rentan $(<20 \&>35)$ & 40,3 & 59,7 & 47,6 & 52,4 & 54,2 & 45,8 \\
\hline \multicolumn{7}{|l|}{ Jumlah Anak } \\
\hline$\leq 2$ anak & 42,5 & 57,5 & 48,4 & 51,6 & 53,4 & 46,6 \\
\hline 3-4 anak & 39,9 & 60,1 & 44,6 & 55,4 & 52,8 & 47,2 \\
\hline$>4$ anak & 30,8 & 69,2 & 31,5 & 68,5 & 38,5 & 61,5 \\
\hline \multicolumn{7}{|l|}{ Pendidikan } \\
\hline Tidak Sekolah & 18 & 82 & 19,7 & 80,3 & 22,5 & 77,5 \\
\hline Sekolah Dasar & 28 & 72 & 31,8 & 68,2 & 38,3 & 61,7 \\
\hline Sekolah Menengah I & 52,6 & 47,4 & 54,8 & 45,2 & 58,2 & 41,8 \\
\hline Pendidikan Tinggi & 70,5 & 29,5 & 69,8 & 30,2 & 70,9 & 29,1 \\
\hline \multicolumn{7}{|l|}{ Status Bekerja } \\
\hline Tidak Bekerja & 46,9 & 53,1 & 50,6 & 49,4 & 52,8 & 47,2 \\
\hline Bekerja & 35,8 & 64,2 & 43 & 57 & 52,5 & 47,5 \\
\hline \multicolumn{7}{|l|}{ Status Kekayaan } \\
\hline Sangat bawah & 6,5 & 93,5 & 11,7 & 88,3 & 17,6 & 82,4 \\
\hline Bawah & 20,5 & 79,5 & 32,2 & 67,8 & 36,2 & 63,8 \\
\hline Menengah & 38,4 & 61,6 & 48,8 & 51,2 & 52,1 & 47,9 \\
\hline Tinggi & 61,6 & 38,4 & 64,4 & 35,6 & 66,6 & 33,4 \\
\hline Sangat Tinggi & 83,2 & 16,8 & 81,6 & 18,4 & 82,8 & 17,2 \\
\hline \multicolumn{7}{|l|}{ Pendidikan Pasangan } \\
\hline Tidak Sekolah & 16,1 & 83,9 & 17,3 & 82,7 & 31,4 & 68,6 \\
\hline Sekolah Dasar & 26,2 & 73,8 & 29,8 & 70,2 & 36,6 & 63,4 \\
\hline Sekolah Menengah I & 51,1 & 48,9 & 54,2 & 45,8 & 58,1 & 41,9 \\
\hline Pendidikan Tinggi & 70,1 & 29,9 & 72,8 & 27,2 & 73,9 & 26,1 \\
\hline \multicolumn{7}{|l|}{ Status Bekerja } \\
\hline Tidak Bekerja & 55,1 & 44,9 & 51,4 & 48,6 & 63,9 & 36,1 \\
\hline Bekerja & 40,2 & 59,8 & 46 & 54 & 52,3 & 47,7 \\
\hline
\end{tabular}

Sumber. Olahan SDKI 2007, 2012 dan 2017 


\section{Tren unmet need di Indonesia}

Pada grafik 1, kecenderungan kejadian unmet need meningkat sebesar $8 \%$ dalam sepuluh tahun terakhir dengan unmet need dengan tujuan menjarangkan meningkat $1,5 \%$ dan unmet need dengan tujuan membatasi meningkat $6,5 \%$.

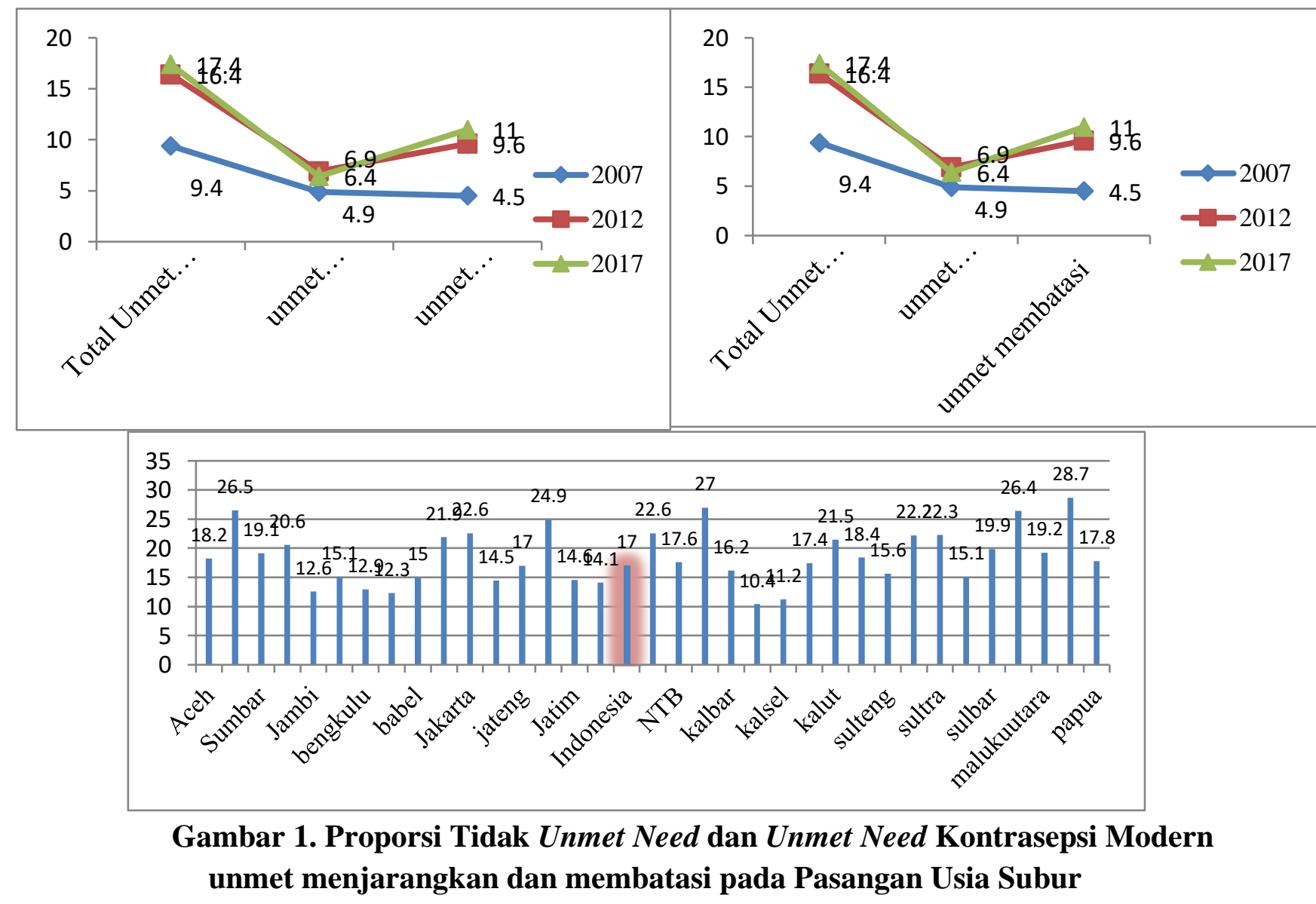

Distribusi unmet need kontrasepsi modern mengalami disparitas di sejumlah wilayah. Sebagian besar wilayah di Indonesia mengalami unmet need kontrasepsi modern dengan dominasi wilayah timur. Sementara di wilayah bagian Barat, beberapa wilayah di pulau Sumatera mengalami unmet need.

\section{Tren unmet need berdasarkan wilayah urban dan rural}

Tabel 2, menggambarkan persentase unmet need lebih besar pada PUS di wilayah pedesaan pada tahun 2007. Namun pada tahun 2012 dan 2017, proporsi unmet need lebih banyak terjadi pada PUS di daerah perkotaan. Pada tingkat wilayah, gambaran karakteristik individu seluruh populasi sampel menunjukkan profil yang hampir serupa. Pada tabel 4.2, menunjukkan persentase perempuan dengan umur rentan lebih banyak di wilayah rural pada tahun 2007 dan 2012. Sementara di tahun 2017, menunjukkan persentase umur rentan lebih tinggi di wilayah urban. Rata-rata pasangan usia subur memiliki jumlah anak yang lebih banyak di wilayah rural dibandingkan PUS di wilayah urban. Selama kurun waktu sepuluh tahun, rata-rata PUS dengan jumlah anak sedikit $(\leq 2)$ semakin meningkat di wilayah urban. 
Tabel 2. Proporsi Unmet Need Kontrasepsi Modern Berdasarkan Wilayah Tempat Tinggal

\begin{tabular}{|c|c|c|c|c|c|c|c|c|c|c|c|c|}
\hline \multirow[t]{3}{*}{ Variabel } & \multicolumn{4}{|c|}{ SDKI 2007} & \multicolumn{4}{|c|}{ SDKI 2012} & \multicolumn{4}{|c|}{ SDKI 2017} \\
\hline & \multicolumn{2}{|c|}{ Urban } & \multicolumn{2}{|c|}{ Rural } & \multicolumn{2}{|c|}{ Urban } & \multicolumn{2}{|c|}{ Rural } & \multicolumn{2}{|c|}{ Urban } & \multicolumn{2}{|c|}{ Rural } \\
\hline & $\mathbf{n}$ & $\%$ & $\mathbf{n}$ & $\%$ & $\mathbf{n}$ & $\%$ & $\mathbf{n}$ & $\%$ & $\mathbf{n}$ & $\%$ & $\mathbf{n}$ & $\%$ \\
\hline Tidak unmet need & 6239 & 91,4 & 8997 & 90,1 & 7742 & 82,1 & 9326 & 84,8 & 9253 & 80,4 & 8829 & 85,1 \\
\hline unmet need & 589 & 8,6 & 984 & 9,9 & 1690 & 17,9 & 1667 & 15,2 & 2255 & 19,6 & 1544 & 14,9 \\
\hline
\end{tabular}

Sumber: Olahan Data SDKI 2007,2012 dan 2017

Berdasarkan kategori pendidikan, PUS di wilayah urban rata-rata mengenyam pendidikan yang lebih tinggi dibandingkan PUS di rural. Sementara presentase PUS yang tidak pernah mengenyam pendidikan sama sekali lebih banyak di wilayah rural. Sebaliknya dengan status tidak bekerja pada pasangan usia subur di perkotaan, persentasenya lebih besar dibandingkan dengan PUS di pedesaan. Kuintil kekayaan terbawah masih didominasi PUS di wilayah rural dalam periode sepuluh tahun. Begitupula halnya dengan kuintil kekayaan teratas persentase lebih besar di wilayah urban.

\section{PEMBAHASAN}

Selama periode sepuluh tahun terakhir, unmet need dengan konsep kontrasepsi modern mengalami peningkatan mencapai $8 \%$ di tahun 2017. Pada tahun 2007 angka unmet need masih tergolong rendah walaupun masih jauh dari target nasional pencapaian penurunan unmet need. Kemudian meningkat di tahun 2012 dan cenderung stagnan di 2017. Peningkatan unmet need kontrasepsi modern seiring dengan peningkatan pemakaian kontrasepsi tradisional(1). Semakin meningkatnya penggunaan tradisional di beberapa daerah turut menyumbang angka unmet need kontrasepsi modern. Penggunaan tradisional dalam praktiknya menunjukkan beberapa pasangan usia subur justru menjadikan kontrasepsi tradisional sebagai pilihan karena dianggap tidak bertentangan dengan ajaran dan nilai-nilai keagamaan (9) sehingga pemakaian kontrasepsi tradisional di beberapa provinsi terlihat meningkat, seperti di Bengkulu (naik 1,9 persen), Sulawesi Utara (naik 2 persen), Kalimantan Tengah (naik 4,6 persen), dan Sulawesi Tenggara (naik 2,6 persen). Hasil studi kualitatif sebelumnya mengungkapkan beberapa alasan penggunaan metode tradisional pada beberapa PUS disebabkan karena tidak bertentangan dengan agama, informasi dari pihak lain (tetangga, orang tua), mitos kemandulan, pertentangan suami, efek samping dan sebagainya. Hal ini menjadi bukti masih kurangnya informasi tentang KB sehingga pengetahuan PUS tentang alokon hanya berdasarkan informasi sekadarnya yang diperoleh dari akseptor lain berdasarkan pengalaman masing-masing.

Berdasarkan kebutuhan, persentase unmet need dengan tujuan membatasi lebih besar dibandingkan unmet need dengan tujuan menjarangkan dengan peningkatan 1,5\% untuk menjarangkan dan 6,5\% untuk membatasi. Proporsi unmet need dengan tujuan membatasi memiliki presentase yang lebih besar dibandingkan dengan tujuan menjarangkan seiring dengan fakta bahwa sebagian besar PUS menginginkan anak dengan jumlah ideal 1 dan/atau 2 anak. Hal ini didukung dengan data lain dalam studi ini yang menunjukkan peningkatan PUS yang memiliki jumlah anak sedikit $(\leq 2)$. Namun karena berbagai faktor, perempuan 
yang awalnya berkebutuhan untuk membatasi jumlah anak, faktanya mengalami kehamilan kembali setelah memiliki 1 atau 2 anak (10). Hal inilah yang juga menjadi alasan meningkatnya unmet need kontrasepsi modern.

Kecenderungan unmet need menurut wilayah perkotaan dan pedesaan juga mengalami peningkatan. PUS yang mengalami unmet need justru mengalami peningkatan di urban dan menurun di wilayah rural walaupun penurunannya tidak signifikan. Karakteristik PUS di urban dan rural tidak menunjukkan perbedaan sehingga baik di perkotaan dan pedesaan dapat mengalami unmet need. Kejadian unmet need di wilayah rural dipengaruhi oleh faktor dukungan suami sementara di wilayah urban disebabkan karena keluhan efek samping (11). Data SDKI mengungkapkan bahwa alasan utama PUS tidak menggunakan kontrasepsi adalah keluhan efek samping. Hal ini juga didukung oleh hasil studi kualitatif bahwa sebagian besar PUS di perkotaan mengalami unmet need karena pengalaman efek dari penggunaan kontrasepsi sebelumnya.

Hasil studi juga menunjukan bahwa tingkat penggunaan kontrasepsi dan kebutuhan KB yang tidak terpenuhi (unmet need) di tingkat kabupaten/kota sangat bervariasi. Sebagian besar unmet need tertinggi berada di wilayah timur Indonesia. Berdasarkan penelusuran pustaka, disparitas unmet need setiap propinsi tidak dapat diukur berdasarkan karakteristik individu karena setiap daerah hampir seluruhnya memiliki karakteristik yang sama. Perbedaan setiap daerah disebabkan karena adanya perbedaan implementasi kebijakan KB akibat adanya desentralisasi sehingga maksimalnya program dan pelayanan $\mathrm{KB}$ tergantung pada birokrasi daerah masing-masing (12). Tingkat komitmen yang bervariasi antar kabupaten/kota dan sering terjadinya stock-out juga mempengaruhi ketersediaan kontrasepsi dan pelayanan KB (13). Dengan perubahan kelembagaan tersebut juga menyebabkan posisi dan tugas PLKB (Petugas Lapangan Keluarga Berencana), yang selama ini menjadi ujung tombak pelaksanaan KB di kabupaten/kota juga menjadi tidak jelas. Di samping itu, dukungan anggaran di beberapa pemerintah daerah untuk menjalankan program KB tidak terlalu signifikan (14).

Hal ini juga berdasarkan pada kondisi ekonomi, pendidikan, dan infrastrukrur Indonesia bagian timur secara umum tidak lebih baik dibanding dengan kondisi Indonesia bagian barat, sehingga tingkat unmet need KB lebih tinggi di wilayah Indonesia bagian timur (15). Literatur penelitian menyebutkan sumber daya kesehatan berdasarkan luas area berhubungan dengan unmet need KB di Indonesia terutama unmet need untuk penjarangan. Semakin tinggi rasio sumber daya kesehatan per $1.000 \mathrm{~km} 2$ semakin rendah angka unmet need KB. Hal ini dapat terjadi karena persebaran sumber daya kesehatan yang tidak merata (12). Kebijakan pemerintah selama ini hanya memprioritaskan jumlah tenaga kesehatan yang memadai saja. Selain itu, kualitas layanan dapat memengaruhi hasil layanan KB. Tenaga kesehatan kurang terlatih memengaruhi jumlah akseptor KB (16)

Saat ini perencanaan kebutuhan tenaga kesehatan di Indonesia disusun berdasarkan rasio per 100.000 penduduk (15). Sistem perencanaan tenaga kesehatan hanya mempertimbangkan jumlah penduduk yang dilayani, sehingga kebutuhan tenaga kesehatan di Pulau Jawa lebih banyak dibandingkan wilayah lain. Jika rasio tenaga kesehatan dilihat berdasarkan luas area layanan, maka kebutuhan tenaga kesehatan di luar Jawa lebih besar dibandingkan wilayah Jawa, hal ini karena area layanan di luar Jawa lebih luas dibandingkan dengan di Jawa. Kondisi tersebut meng- gambarkan kesenjangan distribusi tenaga kesehatan 
antar wilayah di Indonesia. Unmet need juga terjadi karena kurangnya informasi yang diberikan oleh petugas (17). Penyebaran tenaga medis berdasarkan luas area akan sangat bermakna melihat Indonesia adalah negara kepulauan dimana terjadi pemusatan penduduk di pulau Jawa. Selain itu, Kondisi geografis Indonesia yang berpulau-pulau merupakan kendala dalam pencapaian target program KB. Ketimpangan jumlah klinik KB di desa dan kota dan pemusatan klinik di daerah tertentu merupakan kendala bagi pasangan usia subur untuk mengakses klinik KB. Di beberapa daerah terutama luar pulau Jawa, masih banyak penduduk yang mengalami hambatan jarak dan waktu untuk mencapai klinik KB.

Faktor sosial budaya juga menjadi hal yang perlu dipertimbangkan sebagai tantangan unmet need di berbagai propinsi. Berdasarkan literatur sebelumnya, Wilayah timur sebagai wilayah dengan peringkat unmet need tertinggi dipengaruhi oleh faktor budaya setempat. Walaupun pemakaian kontrasepsi di kalangan pasangan usia subur yang menikah mengalami peningkatan $75 \%$ akan tetapi masih terdapat pasangan yang tidak memakai kontrasepsi terutama di Nusa Tenggara Timur (46,3\%) dan Papua $(58,5 \%)$ yang struktur sosial kemasyarakatan masih mengacu pada pimpinan adat dan pemimpin agama(11).

\section{KESIMPULAN DAN SARAN}

Tidak ada perbedaan karakteristik yang menonjol pada PUS maupun pada wilayah urban dan rural. sementara tren unmet need meningkat karena pemakaian tradisional meningkat dan peningkatan unmet need modern lebih dominan di Indonesia bagian timur. Perlu adanya peningkatan promosi terkait penggunaan alat kontrasepsi modern di Indonesia dan perlu adanya perlakuan yang berbeda untuk peningkatan alat kontrasepsi modern sesuai dengan kondisi geografis dan sosial budaya setempat

\section{DAFTAR PUSTAKA}

1. National Population and Family Planning Board (BKKBN), Statistics Indonesia (BPS), Ministry of Health (Kemenkes) and I. Indonesia Demographic and Health Survey, 2017 [Internet]. Jakarta, Indonesia: BKKBN, BPS, Kemenkes and ICF; 2018. 588 p. Available from: https://dhsprogram.com/pubs/pdf/FR342/FR342.pdf

2. Westoff CF. Unmet Need For Modern Contraceptive Methods DHS Analytical Studies. Robey B, editor. Calverton, Maryland, USA: ICF International; 2012.

3. Cottingham J, Germain A, Hunt P, Grosselin J. Family Planning 5 Use of human rights to meet the unmet need for family planning. Lancet [Internet]. 2012;380(9837):17280. Available from: http://dx.doi.org/10.1016/S0140-6736(12)60732-6

4. Cleland J, Harbison S, Shah IH. Unmet Need for Contraception: Issues and Challenges. Stud Fam Plann. 2014;45(2):105-22.

5. Listyaningsih U, Satiti S. Unmet Need: Konsep Yang Masih Perlu Diperdebatkan. Populasi. 2016;24(1):72-90.

6. Mize LS, Robey B. commitment to family planning in Indonesia: BKKBN and USAID's historic partnership. Baltimore: Jhon Hopkins Bloomberg School of Public Health/Center for Communication Programs; 2006.

7. Paramita DF, Baroya N. Hubungan antara Otonomi Perempuan dan Persepsi terhadap Pelayanan Konseling KB dengan Unmet Need KB pada Pasangan Usia Subur di Kecamatan Sumberjambe Kabupaten Jember ( Association between Women ' $s$ Autonomy and Perception of Counseling Services FP Spouse. e-Jurnal Pustaka Ksehatan. 2017;5(2):214-22. 
8. Bellieni C. The Best Age for Pregnancy and Undue Pressures. J Fam Reprod Heal [Internet]. 2016;10(3):104-7. Available from: http://www.ncbi.nlm.nih.gov/pubmed/28101110\%0Ahttp://www.pubmedcentral.nih.g ov/articlerender.fcgi?artid=PMC5241353

9. Kriel Y, Milford C, Cordero J, Suleman F, Beksinska M, Steyn P, et al. Male partner influence on family planning and contraceptive use: Perspectives from community members and healthcare providers in KwaZulu-Natal, South Africa. Reprod Health. 2019;16(1):1-15.

10. UNFPA. Icpd and Human Rights : 20 years of advancing reproductive rights through UN treaty bodies and legal reform [Internet]. 2013. 2013. Available from: www.reproductiverights.org \%7C

11. Putro DAUL. Unmet Need KB di Daerah Perkotaan Dan Pedesaan. 2016.

12. Ariyanti L, Dasuki D, Wilopo SA. Ketersediaan sumber daya kesehatan dan analisis tingkat provinsi. Ber Kedokt Masy. 2017;33(1):49-54.

13. Kemenkes RI. Profil Kesehatan Indonesia 2018 [Indonesia Health Profile 2018] [Internet]. 2019. 207 p. Available from: http://www.depkes.go.id/resources/download/pusdatin/profil-kesehatanindonesia/Data-dan-Informasi_Profil-Kesehatan-Indonesia-2018.pdf

14. Fatoni Z, Astuti Y, Situmorang A, NFN W, Purwaningsih SS. Implementasi Kebijakan Kesehatan Reproduksi Di Indonesia: Sebelum Dan Sesudah Reformasi. J Kependud Indones. 2015;10(1):65.

15. Kementrian Kesehatan RI. Data Informasi Profil Kesehatan Indonesia 2018. J Chem Inf. 2013;53(9):1-1699.

16. Uddin J, Habibullah M, Sabah N. Correlates of unmet need for contraception in Bangladesh : does couples ' concordance in household decision making matter? Contraception [Internet]. 2016;94(1):18-26. Available from: http://dx.doi.org/10.1016/j.contraception.2016.02.026

17. A. M, D. W, A. F, B. M. Determinants of modern contraceptive utilization among married women of reproductive age group in North Shoa Zone, Amhara Region, Ethiopia. Reprod Health [Internet]. 2014;11(1):1-7. Available from: http://ovidsp.ovid.com/ovidweb.cgi?T=JS\&PAGE=reference $\& D=$ emed12\&NEWS=N $\& \mathrm{AN}=2014111648$ 